\title{
Evaluated Result Relationship Probability Code
}

National Cancer Institute

\section{Source}

National Cancer Institute. Evaluated Result Relationship Probability Code. NCI Thesaurus.

Code $C 93833$.

A coded value specifying the likelihood of the identified cause of an adverse event. 